\title{
A percepção de dificuldade de ingressantes no curso de engenharia civil
}

\section{The perception of difficulty of new students in the civil engineering course}

\author{
PASSOS DE OLIVEIRA, Antonio C. S. do N. ${ }^{1}$ \\ MONTEIRO Aline C. de O. ${ }^{2}$ \\ SOUZA, G. R. de ${ }^{3}$ \\ COSTA, I. M. L. ${ }^{4}$ \\ GALVÃO, J. P. ${ }^{5}$ \\ SANTOS, L. de S. ${ }^{6}$
}

\section{Resumo}

Os relatos de dificuldades por partes dos discentes ingressantes no curso de Engenharia Civil, ofertado por uma instituição de ensino superior pública, no sudeste do estado do Pará, localizada na cidade de Marabá (Brasil), são constantes. Dessa forma, este artigo buscou, por meio de um questionário semiaberto, identificar que dificuldades eram percebidas por esses ingressantes no curso. Percebeu-se que eles visualizam que os conhecimentos prévios em Ciências Exatas e o tempo (disponível) como as principais dificuldades. Notou-se, que apesar de empiricamente, perceber-se que eles têm pouco domínio em tecnologia digitais de informação e comunicação, isso não é percebido por eles.

Palavras-chave: competência, aprendizagem, perceção, atitude

\begin{abstract}
Reports of difficulties on the part of students entering the Civil Engineering course offered by a public higher education institution in the southeast of the state of Pará, located in the city of Marabá (Brazil), are constant. Thus, the present study aimed to identify which difficulties were perceived by those entering the course through a semi- open questionnaire. As a result, it was noted that the students find that previous knowledge in Exact Sciences and time (available) constitute the primary difficulties. It was also found that, although empirically, they have little domain in digital information and communications technology, a fact that was not perceived by the students themselves.
\end{abstract}

Keywords: competence, learning, perception, attitude

\section{Introdução}

Ao ingressar em uma universidade a rotina dos calouros é modificada (OLIVEIRA \& DIAS, 2014), a reação à mudança do ingressante poderá afetar em sua trajetória acadêmica, uma vez que, o curso superior exige

\footnotetext{
${ }^{1}$ Universidade Federal do Sul e Sudeste do Pará. Brasil. Email: profnasicmento@unifesspa.edu.br

2 Universidade Federal do Sul e Sudeste do Pará. Brasil. E-mail: alinec.oliveiram@gmail.com

${ }^{3}$ Universidade Federal do Sul e Sudeste do Pará. Brasil. E-mail: geeo.rsouza@gmail.com

${ }^{4}$ Universidade Federal do Sul e Sudeste do Pará. Brasil. E-mail: Isidoro.lameira@gmail.com

${ }^{5}$ Universidade Federal do Sul e Sudeste do Pará. Brasil. E-mail: jamilson34@hotmail.com

${ }^{6}$ Universidade Federal do Sul e Sudeste do Pará. Brasil. E-mail: leidiane327@hotmail.com
} 
competências ligadas à organização do tempo, concentração e disciplina para um bom aproveitamento. A identificação de quais dificuldades são sentidas pelos discentes se faz necessária, pois pode contribuir para formulação de políticas que busquem a redução dos índices de evasão no primeiro semestre do curso (Bardagi \& Hutz, 2011).

De acordo com Dias et al. (2019) foi observado que houve dificuldades dos calouros na adaptação aos fatores da vida acadêmica, dos quais destacou a dificuldade em gerir o tempo para a execução das atividades propostas.

Segundo Pascarella \& Terenzini (2005) e Teixeira et al. (2012), as experiências vividas no primeiro ano da universidade são de grande importância para a permanência, formação e sucesso acadêmico dos estudantes.

Neste sentido, este trabalho visa destacar as dificuldades percebidas pelos discentes do ensino superior nos períodos iniciais do curso de Engenharia Civil. Para recorte de análise se irá adotar o primeiro semestre do curso ofertado pelo Instituto de Geociências e Engenharia (IGE) da Universidade Federal do Sul e Sudeste do Pará (Unifesspa), localizada na cidade de Marabá, sudeste do estado do Pará, Brasil.

Com base no percurso metodológico presente em Dias et al. (2019), foram verificadas quais dificuldades eram percebidas no ingresso na rotina de estudante universitário, para isso fez uso de um questionário semiaberto.

\section{Metodologia}

Com o objetivo de identificar as dificuldades percebidas pelos ingressantes do curso de Engenharia Civil do IGE/Unifesspa, foi elaborado um questionário semiaberto e compartilhado via correio eletrônico e por ficheiro de compartilhamento de mensagens instantâneas, tendo como público alvo os discentes ingressantes do curso de Engenharia Civil, do Instituto de Geociências e Engenharia (IGE), da Universidade Federal do Sul e Sudeste do Pará (Unifesspa). De um universo de 45 discentes que frequentam regularmente as aulas, o questionário obteve as respostas de 24 deles .

Foram realizadas perguntas fechadas com múltipla escolha na escala de 1 à 5 onde: 1 (Algo muito difícil); 2 (Algo difícil); 3 (Sou indiferente); 4 (Algo fácil); 5 (Algo muito fácil). Sendo esses questionamentos: "O uso de aprendizagem baseada em competências se propõe a estimular que os conhecimentos seja buscados com protagonismo, para que se possa demonstrar habilidade e atitude em utilizá-los, em relação a essa afirmação, você considera o uso dessa estratégia de aprendizagem", e, "Utilizar seus conhecimentos prévios nas questões e problematizações das componentes curriculares, é algo que você considera".

A outra pergunta fechada adotada foi: "Quais dos temas a seguir você considera que demanda de mais conhecimentos prévios para ter menos dificuldade ao ingressar no curso de Engenharia Civil". Para qual eram dadas as opções: Humanidades, Ciências Exatas, Literacia científica, Literacia digital, Artes, Conhecimentos Específicos e Outro (informar a seguir). O intuito dessa pergunta era avaliar em qual área os discentes ingressantes percebem que necessitam ter conhecimento prévio.

Por fim, foi realizada uma pergunta aberta: "Diga apenas duas palavras que expressem suas maiores dificuldades ao ingressar no curso de Engenharia Civil". Essa pergunta se propunha em avaliar que palavras eles atrelam as suas percepções de dificuldade, para que se possa inferir a visão que eles construíram sobre o ingresso deles no curso.

\section{Resultados}

Em relação à percepção dos discentes ingressantes sobre o uso da aprendizagem baseada em competências, $41,7 \%$ dos respondentes consideram algo fácil e $20,8 \%$ deles são indiferentes ao tema (Figura 01). Assim, na percepção deles, a diferença pedagógica existente entre aulas expositivas e aulas que foque em um percurso 
mais ligado ao protagonismo e autonomia (aprendizagem baseada em competências) não representa um obstáculo significativo (Figura 1).

Em relação a utilização dos conhecimentos prévios, nas nas questões e problematizações das componentes curriculares, os discentes ingressantes que responderam o questionário foram $25 \%$ indiferente e $41,7 \%$ com uma percepção de algo fácil.

Pode-se esperar então, pelo número de respondentes (24) em relação ao universo de discentes ingressantes que regularmente frequentam as aulas (45), que ao mais de $50 \%$ não considera algo difícil utilizar conhecimentos prévios, nem tão pouco, a modificação de abordagem pedagógica vivenciada.

Figura 1

Percentual dos respondentes em relação a aprendizagem aseada em competências. Sendo 1 (Algo muito difícil); 2 (Algo difícil); 3 (Sou indiferente); 4 (Algo fácil); 5 (Algo muito fácil).

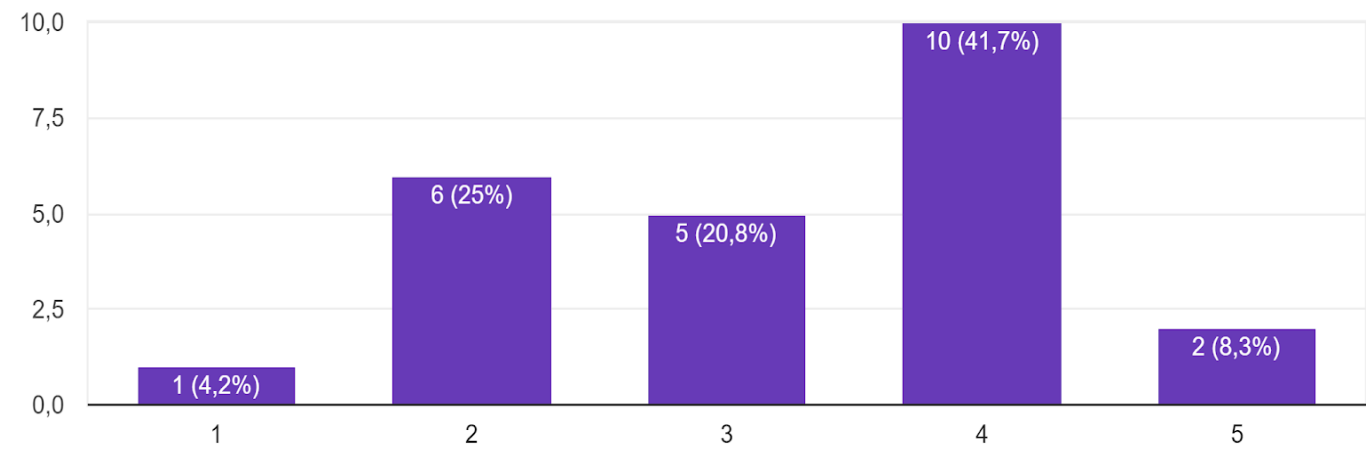

Fonte: Autores, 2021

Figura 2

Percentual dos respondentes em relação ao uso de conhecimentos prévios em questões e problematizações das componentes curriculares.

Sendo: 1 (Algo muito difícil); 2 (Algo difícil); 3 (Sou indiferente); 4 (Algo fácil); 5 (Algo muito fácil).

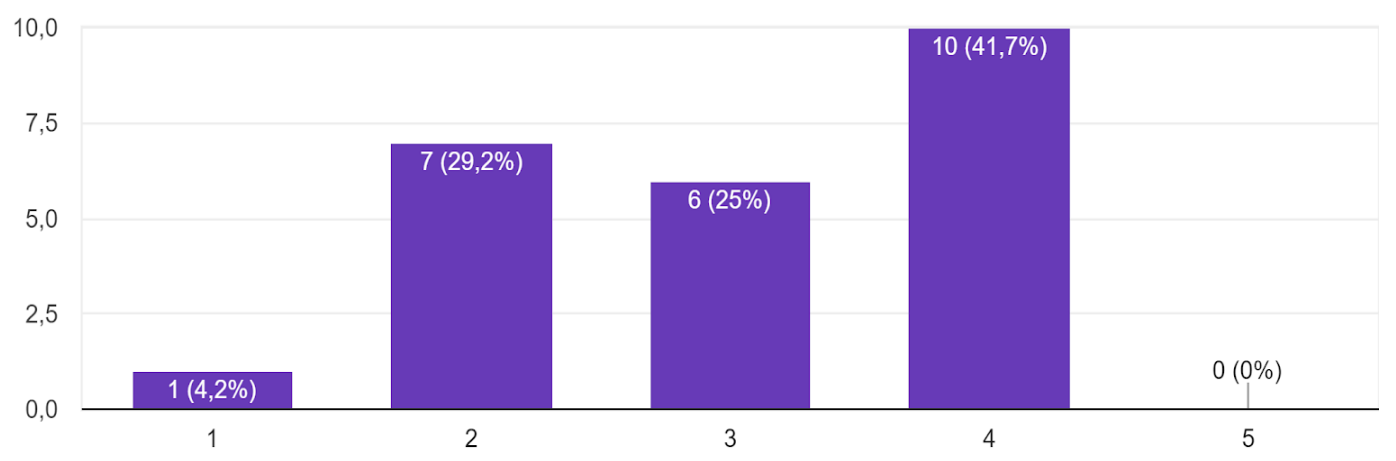

Fonte: Autores, 2021

No tocante aos conhecimentos prévios listados para que os discentes ingressantes opinassem (tabela 01), foi preponderante os conhecimentos ligados às Ciências Exatas.

Na tabela 01 observa-se que $83,30 \%$ dos entrevistados pontuaram a necessidade de possuir um conhecimento prévio nas disciplinas voltadas a ciências exatas e específicas, sendo que a área de exatas foi a que recebeu maior atenção obtendo $62,50 \%$ da pontuação. 
Percebe-se na Tabela 01 que os discentes não foram reativos aos conhecimentos prévios em Literacia Digital, isso pode significar que: 1 . Eles podem ser nativos digitais, assim, com bom domínio sobre as tecnologias digitais de informação e comunicação; 2 . Que eles tenham uma distorção em relação aos conhecimentos que de fato possuem sobre o tema.

É válido frisar que, com o aumento do trabalho remota, as demandas por automação, os conhecimentos em Literacia Digital se farão cada vez mais presentes no mundo do trabalho, assim, é importante que seja avaliada em qual das duas hipóteses supracitadas os discentes ingressantes realmente se encontram.

Tabela 1

Resposta em relação aos conhecimentos prévios.

$\begin{array}{cc}\begin{array}{l}\text { Quais dos temas a seguir você considera que demanda de mais conhecimentos prévios para } \\ \text { ter menos dificuldade ao ingressar no curso de Engenharia Civil: }\end{array} & 0 \% \\ \text { Humanidades } & 62,50 \% \\ \text { Ciências Exatas } & 12,50 \% \\ \text { Literacia científica } & 0 \% \\ \text { Literacia digital } & 0 \% \\ \text { Artes } & 20,83 \% \\ \text { Conhecimentos Específicos } & 4,16 \% \\ \text { utro (informar a seguir) } & \end{array}$

Fonte: Autores, 2021.

Quando questionados sobre que duas palavras poderiam expressar as dificuldades percebidas por eles, é observado que a gestão do tempo foi a que obteve maiores registros (Figura 3).

Figura 3

Dificuldades ao ingressar no curso.

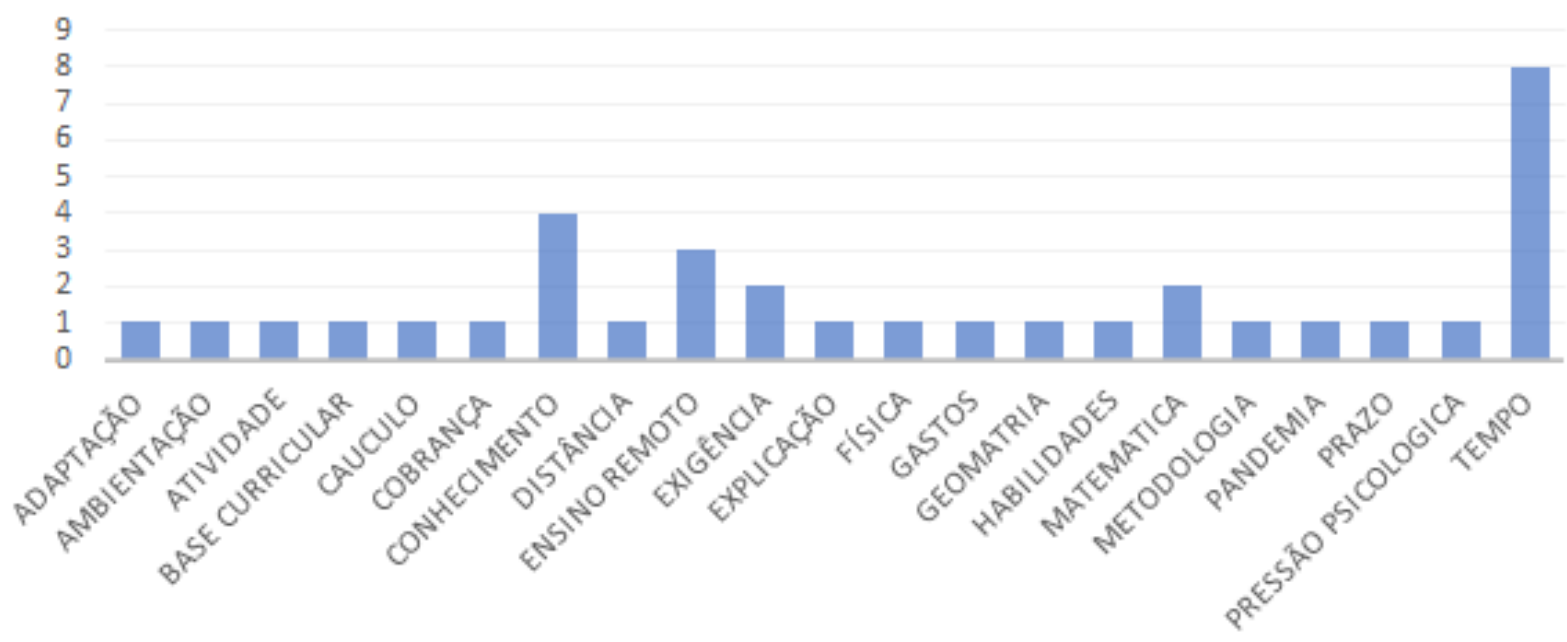

Fonte: Autores, 2021

MacCann, Fogarty, e Roberts (2012) apontam que o tempo é relacionado pelos discentes ingressantes como um obstáculo considerável, sendo ligado, de acordo com os autores, a uma percepção de uma rotina exaustiva e 
estressante, com avaliações rotineiras, grande volume de material demandados e com prazos curtos para entrega de tarefas. Demandando um gerenciamento do tempo.

A dificuldade de administração do tempo dos discentes é algo comum no meio universitário, o que desencadeia uma menor percepção de pouco controle tanto no âmbito pessoal, quanto no profissional (Leite, Tamoyo, e Gunter, 2003), o que pode ser um fator de comprometimento do rendimento acadêmico, como também, da própria qualidade de vida.

\section{Conclusões}

Os resultados apresentados a partir da pesquisa demonstram uma convergência para questões ligadas ao tempo, em relação às dificuldades no curso, o que é sustentado pela literatura de referência. Outra questão preponderante, é em relação aos conhecimentos prévios em Ciências Exatas.

Os discentes ingressantes foram pouco reativos em relação a Literacia Digital, o que pode ser um fator preocupante, caso a percepção deles de não ser uma dificuldade seja uma distorção de avaliação, em relação aos conhecimentos, que de fato, eles dispõem sobre o tema.

Existem limitações em relação ao alcance de resultados com questionários eletrônicos, ainda sim, os resultados podem subsidiar reflexões e ações de planejamento, podendo ser ampliada a prospecção para outros semestres do curso.

\section{Referências bibliográficas}

BARDAGI, M. P.; HUTZ, C. S. Eventos estressores no contexto acadêmico: uma breve revisão da literatura. Interação em Psicologia, 15(1), 111-119, 2011. doi:10.5380/psi.v151.1.170.

DIAS, A. C. G.; CARLOTTO, R. C.; OLIVEIRA, C. T.; TEIXEIRA, M. A. P. Dificuldades percebidas na transição para a universidade. Dificuldades na transição para a universidade. Rev. bras. orientac. prof, Florianópolis , v. 20, n. 1, p. 19-30, jun. 2019. Disponível em $<$ http://pepsic.bvsalud.org/scielo.php?script=sci_arttext\&pid=S167933902019000100003\&lng=pt\&nrm=iso>. Acesso em: 25 mar. 2021. http://dx.doi.org/10.26707/19847270/2019v20n1p19.

LEITE, U. R.;TAMAYO, A.; GÜNTHER, H. Organização do uso do tempo e valores de universitários. Avaliação Psicológica, 2(1), 57-66, 2003. http://pepsic.bvsalud.org/scielo.php?script=sci_arttext\&pid=S167704712003000100007\&lng=pt\&nrm=iso >. Acesso em: 30 março 2021.

MACCANN, C.; FOGARTY, G.; ROBERTS, R. D. Strategies for success in vocational education: Time management is more important for part-time than full-time students. Learning and Individual Differences, 22(5), 618623, 2012 doi:10.1016/j.lindif.2011.09.015

OLIVEIRA, C. T.; DIAS, A. C. G. Dificuldades na Trajetória Universitária e Rede de Apoio de Calouros e Formandos. Psico, 45(2), 187-197, 2014. DOI: https://doi.org/10.15448/1980-8623.2014.2.13347

PASCARELLA, E. T.; TERENZINI, E. T. How college affects students: A third decade of research. (Vol. 2). San Francisco: Jossey-Bass, 2005.

TEIXEIRA, M. A. P.; CASTRO, A. K. S. S.; ZOLTOWSKI, A. P. C. Integração acadêmica e integração social nas primeiras semanas na universidade: percepções de estudantes universitários. Gerais, Rev. Interinst. Psicol., Juiz de fora, v. 5, n. 1, p. 69-85, jun. 2012 . Disponível em 
<http://pepsic.bvsalud.org/scielo.php?script=sci_arttext\&pid=S1983-

$82202012000100006 \&$ Ing=pt\&nrm=iso >. Acesso em: 30 março 2021.

Esta obra está bajo una Licencia Creative Commons

Attribución-NoCommercial 4.0 International

(cc) EY-NO 